\title{
The knowledge management on the design of a generation IV sodium fast reactor project at CEA. The case and methodology applied on the Astrid project
}

\author{
Gilles Rodriguez ${ }^{1,}$, Philippe Amphoux ${ }^{2}$, David Plancq ${ }^{2}$, Edwige Richebois ${ }^{2}$, Frédéric Varaine ${ }^{3}$, and Philippe Bigeon ${ }^{4}$ \\ ${ }^{1}$ CEA - French Alternative Energies and Atomic Energy Commission, CEA-DES Cadarache, IRESNE/DER, Saint Paul lez \\ Durance, France \\ ${ }^{2}$ CEA-DES Cadarache, IRESNE/DER/SESI, Saint Paul lez Durance, France \\ 3 CEA-DES Cadarache, IRESNE/DIMP, Saint Paul lez Durance, France \\ ${ }^{4}$ CEA - CEA Paris-Saclay, Gif-sur-Yvette Cedex, France
}

Received: 12 May 2020 / Received in final form: 31 July 2020 / Accepted: 18 August 2020

\begin{abstract}
From 2010 to 2019, the French Alternative Energies and Atomic Commission (CEA) associated with industrial partners realized the Basic Design of a prototype Sodium Fast Reactor. This project was called ASTRID (ASTRID for Advanced Sodium Technological Reactor for Industrial Demonstration). ASTRID design studies were financed through governmental funds until the end of the basic design. These funds covered also the design studies for the core manufacturing workshop, the refurbishment or construction of large test loops. One year before the term of this Basic Design phase (in 2018), industrial partners, CEA and the French State conducted a review of fast neutrons reactors and fuel cycle strategy. The review which is now translated into the Multiannual Energy Program concluded that the perspective of industrial deployment of Fast Reactors is more distant. Yet it has been concluded to keep this option open, requiring to maintain competences, and to progress on technological barriers and further develop know-how. The strategy for complete closure of nuclear fuel cycle is maintained as a long-term sustainability objective (in the second half of the 21st century). Therefore, as a direct consequence of this decision, the ASTRID project stopped at the end of 2019 at its Basic Design phase. Quickly the question raised on the Knowledge Management (KM) and Know-How capitalization of the huge amount of studies and results realized during ten years (around 23000 technical documents). Moreover the challenge was to realize this KM process in less than one year, before the ASTRID project team definitive split. The paper is presenting an innovative KM methodology which has been created and specifically performed on the ASTRID project. It is based on a series of interviews and video recordings, all transformed into some New KM tools called "MOOK" (MOOK for Management of Organized Online Knowledge). All these MOOKs considered as "data rich contents" are then inter-connected and linked by the ASTRID Product Breakdown Structure to some fundamental documents, for a comprehensive and quick mapping of the project. They finally form an efficient KM tool recorded in a PLM Software (PLM for Product Lifecycle Management). Thus the ASTRID project team has realized a high level and easy-to-use "GPS" (Global Positioning System) tool to keep the ASTRID history, context, knowledge and know-how for years. This KM methodology can be easily adapted to other nuclear projects and needs.
\end{abstract}

\section{Introduction}

From 2010 to 2019, the French Alternative Energies and Atomic Energy Commission (CEA) in collaboration with industrial partners realized the Basic Design of a prototype Sodium Fast Reactor (SFR). This project was called ASTRID (ASTRID for Advanced Sodium Technological

\footnotetext{
* e-mail: gilles.rodriguez@cea.fr
}

Reactor for Industrial Demonstration) [1-3]. One year before the term of its Basic Design phase (in 2018), the Multiannual Energy Program (PPE) concluded that the perspective of industrial deployment of Fast Reactors is more distant. The SFR option has to be kept open, requiring to maintain competences, and to progress on technological barriers and further develop the know-how. The strategy for complete closure of nuclear fuel cycle is considered as a long-term sustainability objective (in the second half of the 21st century). Therefore, the ASTRID 
project stopped at the end of 2019 at its Basic Design phase [4].

At that time the question raised on the Knowledge Management (KM) and Know-How capitalization of these studies and results and associated methods realized during ten years. The challenges to face were: how to provide a Knowledge Management method with higher standards than an electronic library? How to provide innovative and digital methods to get a KM kit usable for the next generation to come (or for even longer time)? How to preserve and store safely these KM tools with an intelligent net allowing a potential quick and efficient restart studies of a prototype Sodium Fast Reactor? Moreover the challenge was to realize this KM process in one year, before the ASTRID project definitive split.

\section{The ASTRID project history}

The genesis of the ASTRID Project was done in the frame of the French Act of 28 June 2006 on sustainable management of radioactive materials and wastes, French Government entrusted CEA (French Commission for Atomic Energy and Alternative Energy) to conduct design studies of ASTRID (Advanced Sodium Technological Reactor for Industrial Demonstration) prototype. After a first period of studies and R\&D jointly performed by the CEA, EDF and AREVA to investigate a range of innovative solutions, the project itself was launched in late 2009 and a project team was set up in the first half of 2010. Funding was granted through an agreement between the French Government and CEA within the scope of the "investments for the future" program.

After 6 years of conceptual design phase, a 4 years basic design phase has started at the beginning of 2016, to design the 600 eMW ASTRID reactor. This phase was scheduled to stop at the end of 2020. But an intermediate project process review decided at the end of 2017 to reconsider the project objectives and to redesign it in two years (2018-2019). The New ASTRID power was reduced to 150 eMW (called New ASTRID or ASTRID150) and the design has to be downsized using to Design To Cost (DTC) approach in order to strictly reduce the estimated investment cost. As expressed in the introduction, the decision was taken to stop the project at the end of 2019 with the completion of the New ASTRID (150 MWe) preliminary redesign according to the DTC analysis. Starting in Oct.2018 and during the whole 2019 year, along with the end of the New ASTRID design, the Knowledge Management process was carried out.

\section{The knowledge management project idea}

The initial Project Idea was to define and realize a high level and easy-to-use "GPS" (Global Positioning System) tool to keep the ASTRID history, context, knowledge and know-how for years - see Figure 1.

After having checked several already known KM methods and contacted KM experts, an innovative KM methodology has been created and specifically applied as a

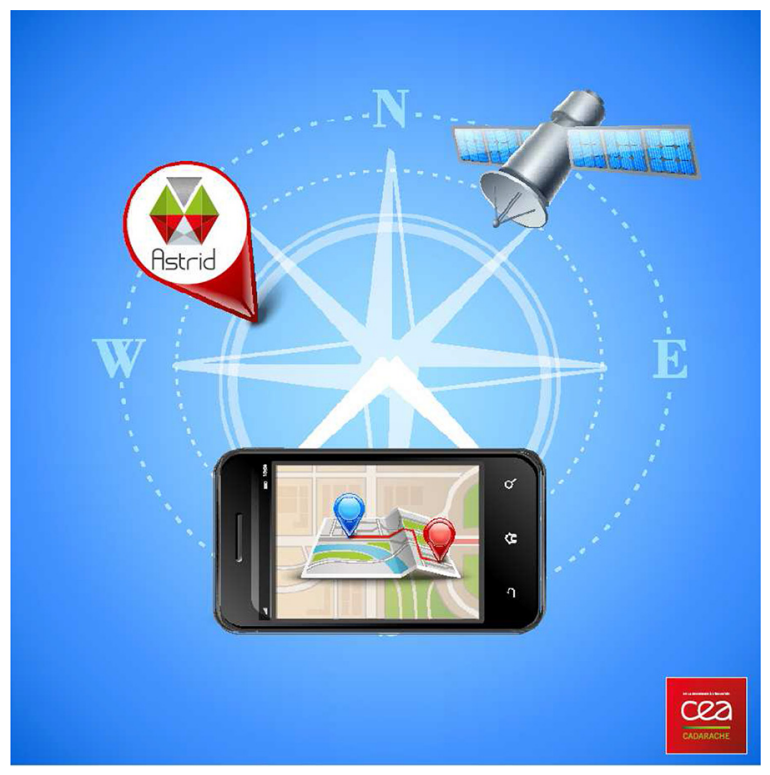

Fig. 1. Schematic basic idea of the ASTRID knowledge management process.

scale 1 test on the ASTRID project. In the past nuclear civil program, CEA usually experienced KM technics especially in the field of Sodium Fast Reactor where the actions carried out were remarkable [5]. These methods - the MADONA encyclopedia for instance [6-8] - were usually focusing on report synthesis and a large list of recommended and relevant documents covering a whole system (Sodium Fast Reactor). In that case, the Knowledge Management process was specifically used on a unique project and with an extensive use of videos.

This KM methodology is based on a series of expert or project actor's interviews and video recordings, all transformed into some New KM tools called "MOOK" (MOOK for Management of Organized Online Knowledge). All these MOOKs are considered as "Data-Rich Contents". At the beginning the material starts from a video recording of experts explaining their own field of specialty. But these videos will then be transformed to "MOOKs data rich content' because each of them will have to respect the following rules:

- they will recommend and provide links to a series of 15 to max 20 documents or deliverables which are highly rated and recommended by the expert to "dive in depth in the subject",

- they will respect some prerequisite such as the presentation structure, an expert position on the lessons learned and recommendation, a duration limit,

- all MOOKs will then be remastered to produce on-line chaptering allowing a quick and easy access within all sub-chapters of the MOOK.

Finally all these MOOKs are inter-connected and linked to and by the ASTRID Product Breakdown Structure and to the recommended documents (Fig. 2), for a comprehensive and quick mapping of the project. By the active links with documents, it becomes possible to connect to the main configurations of ASTRID and therefore to 


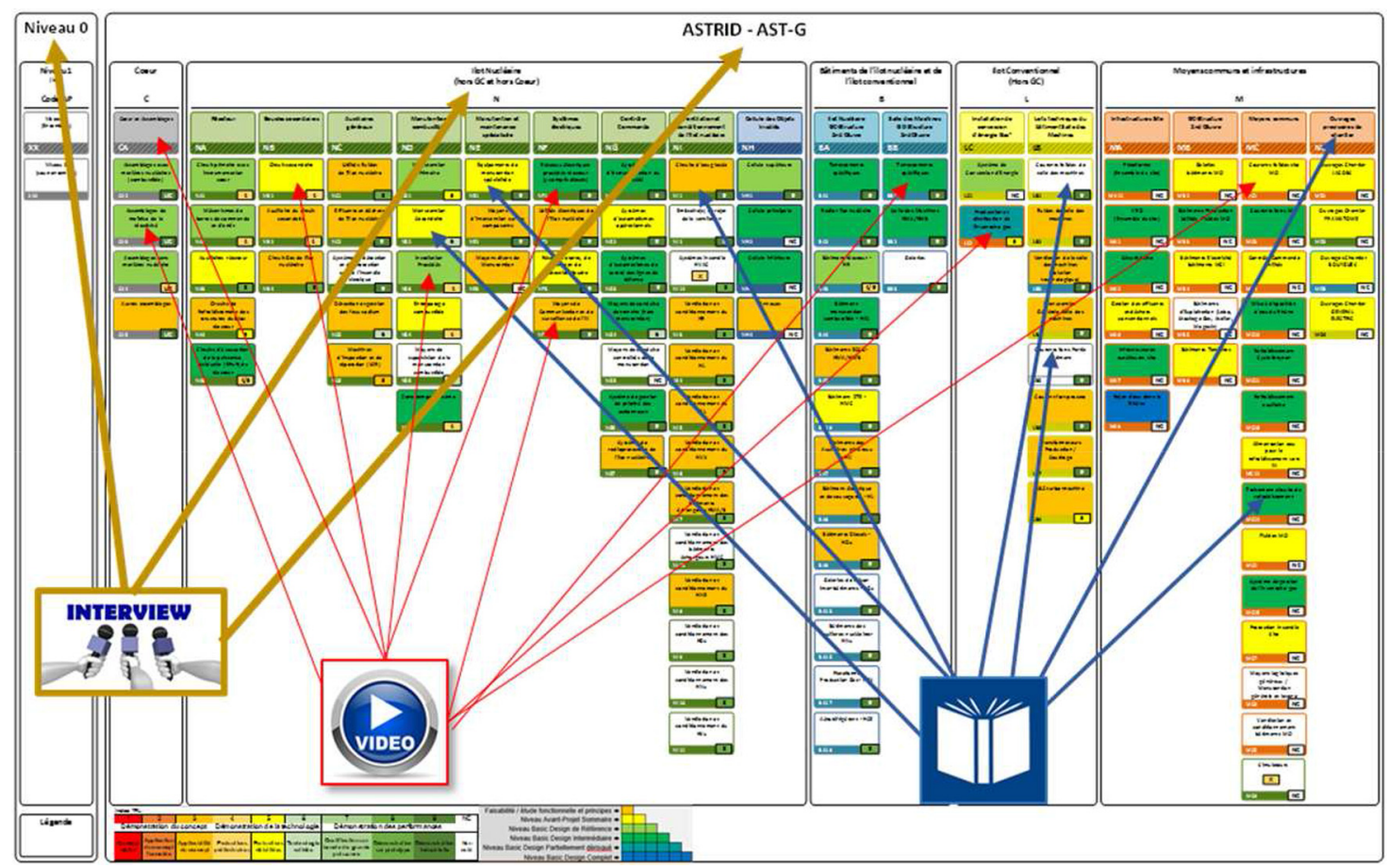

Fig. 2. Representation of MOOKS / Interviews / Relevant Document in connection with the ASTRID Project Product Breakdown Structure (Level 3).

repossess the global vision. They finally form an efficient rich KM tool recorded in the ASTRID PLM Software (PLM for Product Lifecycle Management).

The use of a PLM Software to realize the Project Knowledge Management appears to be an evidence at the starting point of this KM Project. Indeed, for the past two years, the management of configuration was driven with a PLM Software. With the increasing levels of complexity and connectivity involved over time, the standard project management tools quickly started to reach their limits, making it more and more complex to control configuration issues, and the capacity of accurate synthesis became more time consuming. An electronic project library where all deliverables are stored but not rated cannot reflect a project complexity because it is not endorsed to a Project Breakdown Structure. Thus, the ASTRID project unit opted at the basic design phase for the implementation of a Product Lifecycle Management (PLM) software package, to monitor the progress of studies and to manage configuration issues. The following management processes have been gradually implemented: product breakdown structure, associated definition files, functional breakdown structure, risk management, and qualification program. Furthermore, the innovation at the KM level of this project was to use the PLM to implement the knowledge capitalization process too.

\section{The MOOK, step by step realization process}

To realize a series of MOOK/Interview/Synthesis reports allowing a quick mapping of the project, the following process has been adopted.

\subsection{Step 1: Realize a selection of the material needed}

This first step selection is done jointly by all the teams project to define commonly - according to the Product breakdown Structure - which subject will require MOOK, which will require only a synthesis report, which will need both. In addition we defined the list of interviews of key persons we wanted to record (Fig. 2). Often, the question raised on how to judge what is needed: a MOOK? a written document? or both? The key message on this is that usually MOOK is required when the system in itself is complex, the TRL rather low and/ or the system documentation rather incomplete. In other cases it was usually a team's judgement to determine if a MOOK was necessary or not. This first step is of major importance and deeply relies on the team organization working in an agile management mode. We deeply promote co-working and codecision in this first step. Indeed, it was important to get the fully support of all team members (and future MOOK actors) at this very first step level.

\subsection{Step 2: Prepare your .ppt presentation (Fig. 3)}

In this step, every identified expert has to prepare its PowerPoint ${ }^{\circledR}$ format (.pptx) presentation which will be the backbone of the future MOOK. The preparation of the . ppt presentation has to respect strict rules according to a unique model for all presenters:

- Slide 1: Present a clear and simple title of the presentation.

- Slide 2: Present yourself explaining your skills and why you will perform this MOOK.

- Slide 3: Present a detailed Table Of Content (TOC) of your presentation. This rule is very important to allow the final video post processing (chaptering according to the TOC). 


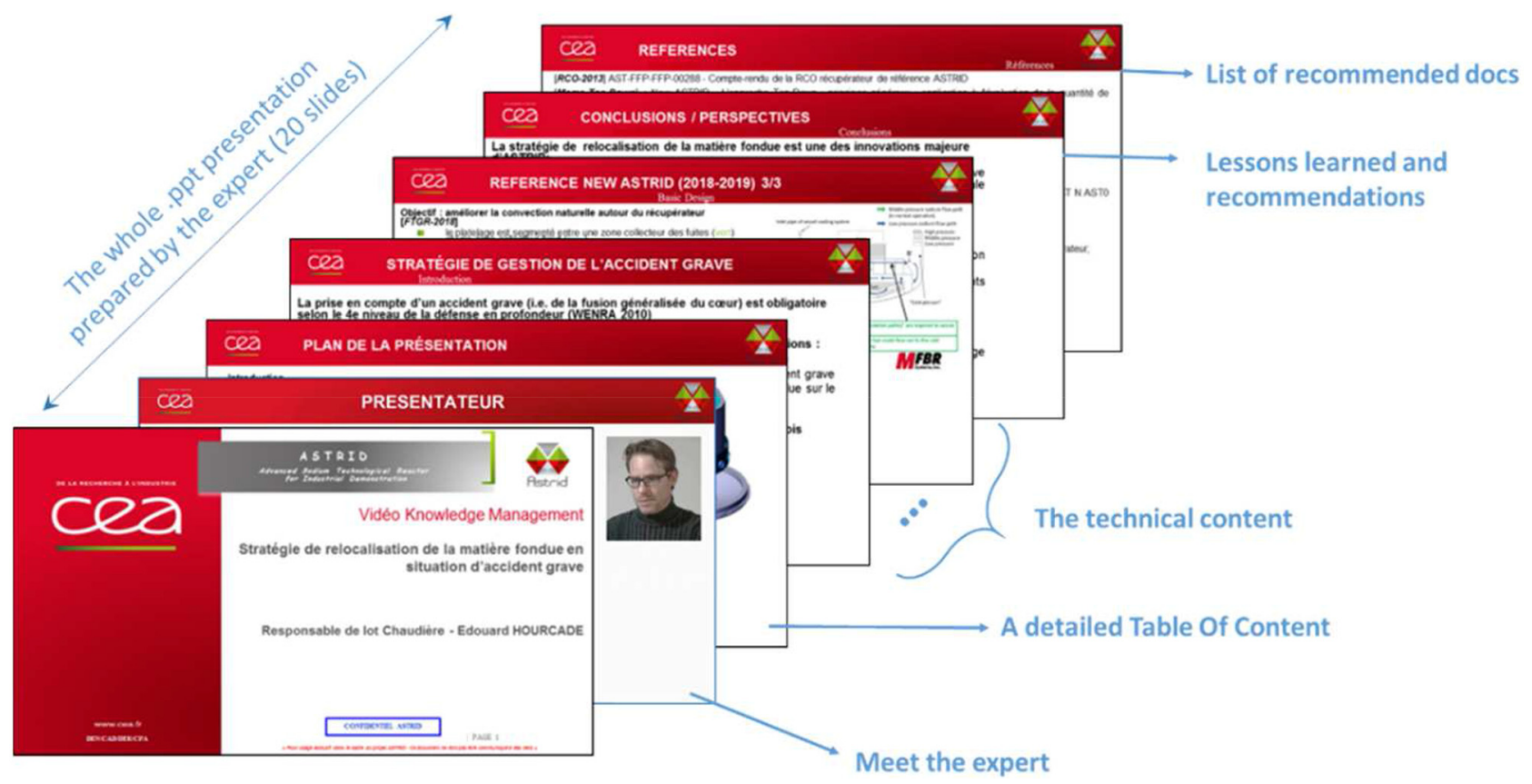

Fig. 3. The second step of a MOOK creation: Preparation of the ppt presentation by the expert.

- Slide 4 to XX: Present the technical content of your presentation. We recommend a maximum length of 20 to 40 slides.

- Slide XX + 1: Provide minimum one slide with Recommendations / Experimental Feedback / Lessons learned.

- Last Slide: Provide a detailed list of referenced documents that you recommend to go deeper in the subject knowledge (it is defined as the expert's "bedside book" list).

The whole .ppt presentation should represent a total of 40-50 slides allowing a video recording duration of 30-50 min maximum. In all slides, the expert will let the right down corner empty (no text nor images) to allow the portrait-video incorporation during its speech. The expert will then gather its finalized .ppt presentation and the related document list. He will submitt this final presentation to a technical reviewed board (auto-)selected among the project team. The expert is doing its speech in support to its presentation and the reviewers are checking content and form. After taking into account all comments, the expert is ready to start the video recording step.

\subsection{Step 3: Record your video-presentation}

The video recording can be done in two manners: - you can do it in your office using a specific tool of PowerPoint Microsoft ${ }^{\circledR}$ Software where you can record in video mode your own .ppt presentation in diaporama mode. A practical tip is to create a private Skype ${ }^{\circledR}$ meeting to get a feedback view of your own webcam that you can insert online on the bottom right of your screen during the diaporama show. Using this method allows the expert to record its own video-presentation in his office, without the need of an additional person and video recording material.
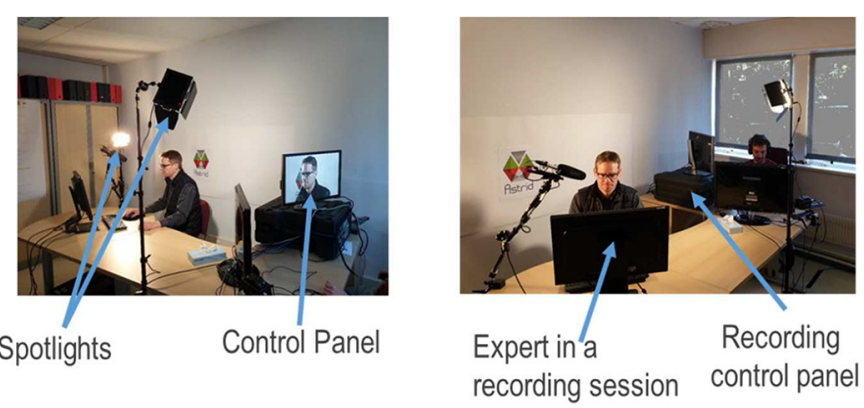

Fig. 4. Third step of a MOOK creation - Video-Recording of the presentation (here in a remote video Lab).

- in ASTRID case, the project team had the opportunity to get a small remote video laboratory (Fig. 4). This video laboratory configuration allows to record on two seperate lines the .ppt presentation in diaporama mode, and the expert portrait (close-up) with his voice. The final editing is done afterwards.

Usually the video-presentation recording is done in one shot. A "video-cleaning" phase is done afterwards.

\subsection{Step 4: Do the video "cleaning" and chaptering}

The phases of video-cleaning and chaptering were done with a small, cheap and easy-to-use software: CAMTASIA ${ }^{\circledR}$ (this software is oftenly used by the Youtubers to touch up their videos). At this level the obtained material is a videorecording done by an expert. It is a good first step to make Knowledge Capitalization but it is not a MOOK yet (Fig. 5). At this level $90 \%$ of the job have been done. The residual $10 \%$ are devoted to transform the video-presentation to a Rich Content document. 


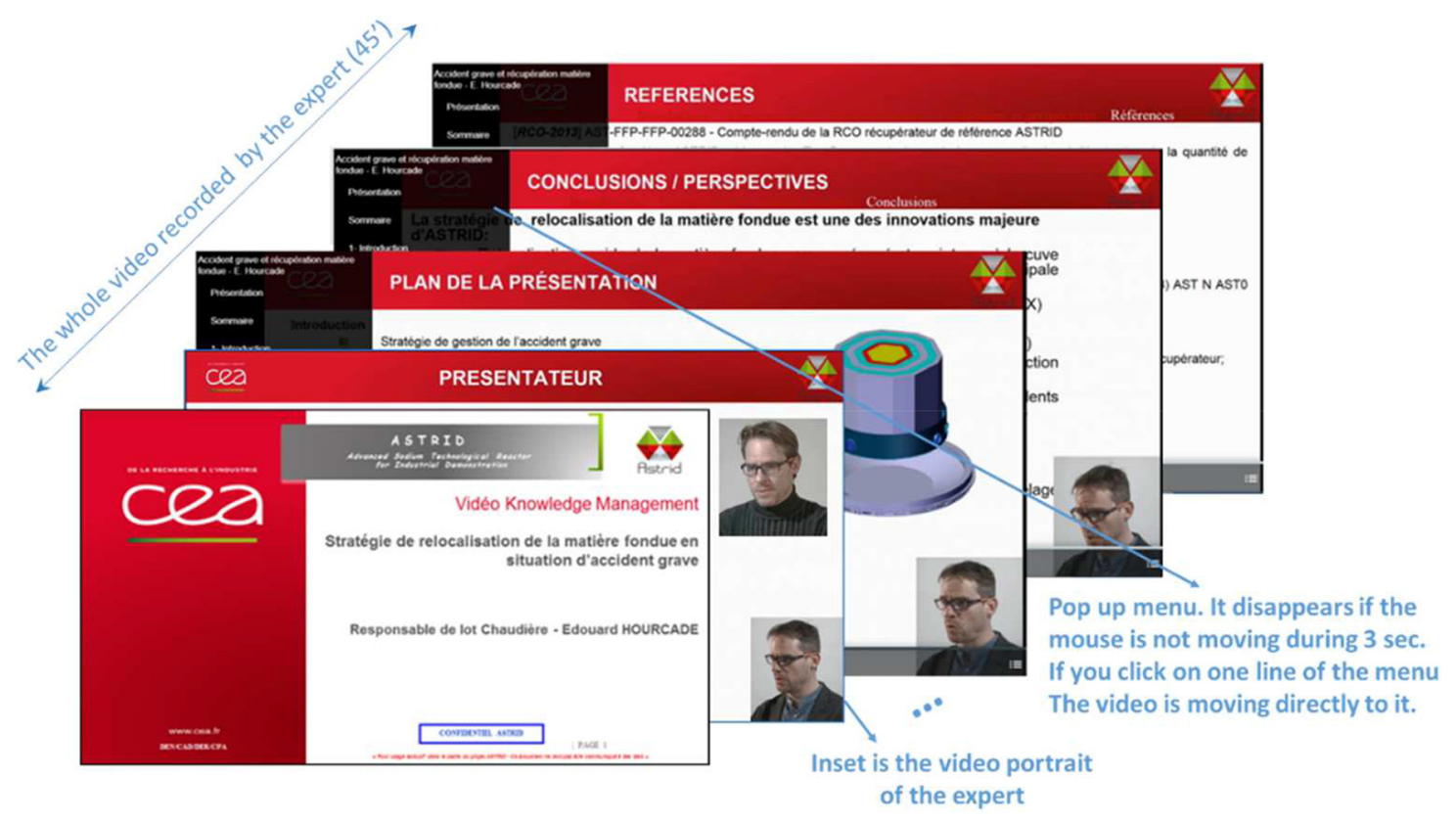

Fig. 5. Step 4 of a MOOK creation: Video post-treatment with CAMTASIA ${ }^{\circledR}$ (Cleaning/Chaptering/Inset).

\subsection{Step 5: Implement the video inside the PLM and realize the trace link with all the recommend documentation and deliverables}

This final step is devoted to address the post-treated video in the PLM Software. The most important now is to realize the trace link between this video positioned in the project PBS and all the related documents recommended by the expert in its video. This net positioned inside the PLM Software is the final material called MOOK (Fig. 6). Now the MOOK is created.

\section{The KM project results}

The results go beyond our expectations. Indeed, in less than one year with a very limited budget, the ASTRID Project was able to define its own KM Methodology assessed on-line by KM French experts (from CEA and FRAMATOME companies). ASTRID project was able to produce more than one hundred of MOOKs realized by CEA actors and experts, and by partners too (mainly FRAMATOME, BOUYGUES and EDF companies). These hundred of MOOKs are all interconnected inside the ASTRID PLM according to the Project Product Breakdown Structure (Fig. 6). They are therefore realizing a rich net (High Level GPS Project) with about 2000 documents highly rated and recommended by the experts. These 2000 documents were pre-selected by the experts among the 25000 documents produced by the project during its whole duration. In addition, specific documents were created to ease the project understanding:

- A detailed Timeline explaining the project life and its evolutionnary context,
- Associated to this, a detailed organisation chart (and its evolution) with all actors of the projects from over ten years,

- Interviews of Key actors relating the contextual vision of the project,

- Open discussion on Project overall feedback, and its SWOT $^{1}$ Analysis.

To achieve this project in a quick and efficient timeframe, the project team adopted an Agile Management method (SCRUM Method) [9]. This method - performed by a cyclic process of one week sprint and half a day scrum meeting - was particularly well fitted to this context. Thanks to this, it must also be highlighted the remarkable enthusiastic personal involvement of all key actors and experts in doing Video-recordings then MOOKs. The Easy-to-do MOOK tool appears to be the most convenient way to allow experts to transfer their knowledge in the best environmental conditions. It is simpler and less complicated than writing "Academic Knowledge Capitalization synthesis reports", furthermore oral communication is less academic and allows to be more outspoken. For the future generation who will have to take over from the ASTRID experts, it is a smart and weel-organized approach. Indeed, it is much more fun and efficient to start watching videos, than being lost in an electronic library with some keywords for the documentation search.

These experiences will have convinced and trained a pool of experts to knowledge management and they now spread this culture inside CEA.

Last but not least this efficient method is frugal because as already explained earlier, the video recording could be done from your own personal computer with a webcam, and

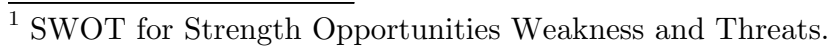




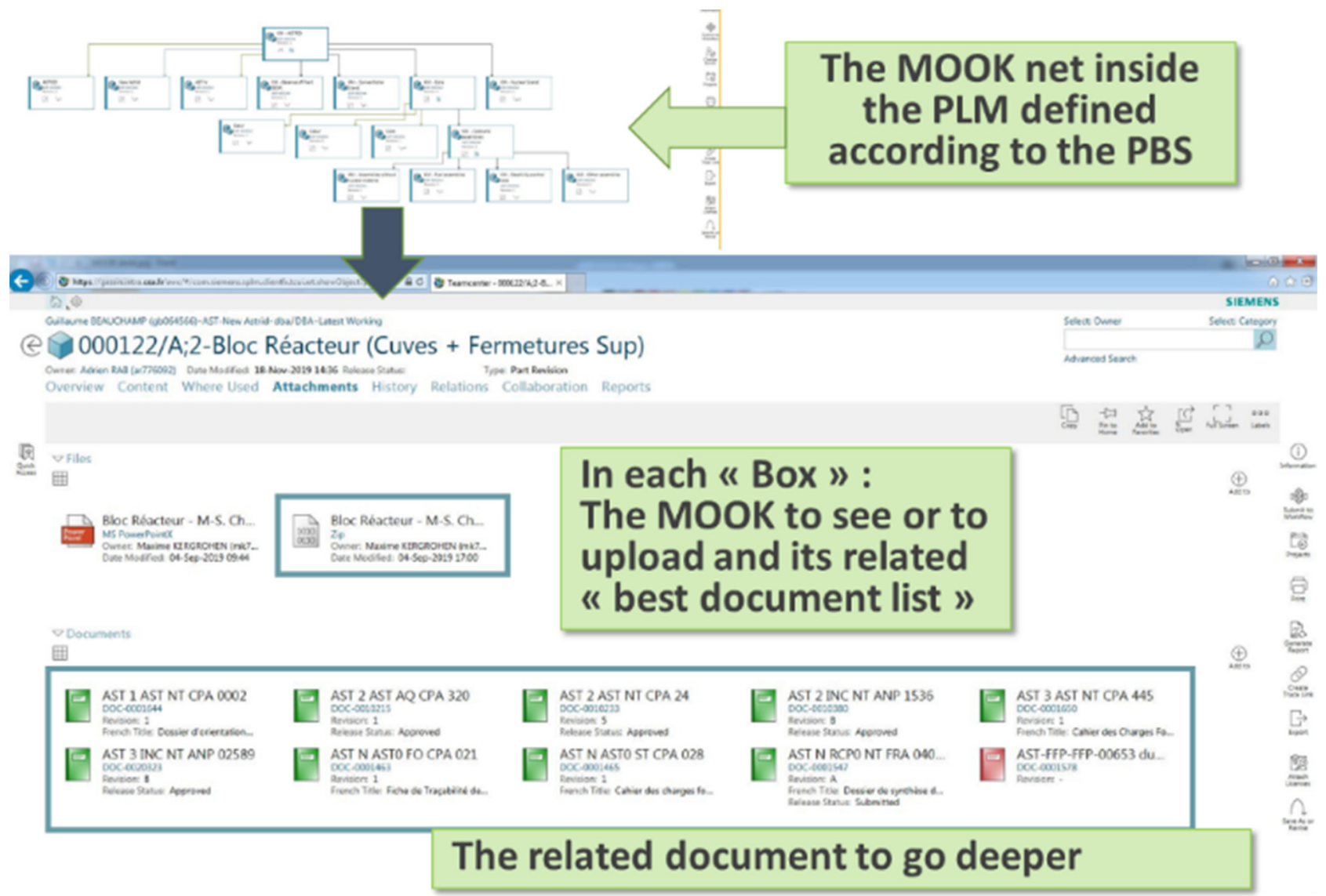

Fig. 6. Step 5 -The post-treated video with its trace-links is implemented inside the PLM Software TEAMCENTER ${ }^{\circledR}$. The MOOK is created!.

the video post treatment is done by a simple and cheap Software $\left(\right.$ CAMTASIA $\left.^{\circledR}\right)$. The price for a whole video recording lab (remote) is less than $15 \mathrm{k} €$ for high sound and image quality.

\section{Future perspective of the MOOK initiative in the knowledge management}

The whole nuclear field is strongly challenged with Knowledge Management. Indeed numerous unfavorable situations are gathered:

- Reactor project are usually long, sometimes extremelly long (over decades).

- Large ratio of projects are stopped before being their final completion. Even less are going to realization.

- Large ratio of projects have to deal to a "stop and go" situation.

- Existing reactors are ageing and the reactor manpower workforce is usually aging in parallel.

- Reactor innovation and safety requests are in constant evolution. It places the reactor design in a difficult situation where you cannot reproduce what was done in the past, and you have no feedback experience.
- Sometimes the Knowledge in nuclear field is very sharp. The specific knowledge can be retained by a very limited number of persons in a company or in the world. This situation can be revealed as problematic if these key persons are moving (retirement, job change).

- Nuclear field is complex and time to acquire knowledge and experience is longer than other industries (i.e. petrochemistry, chemical engineering).

Therefore, to overcome all or some of these situations, the Knowledge Management should be integrated in all nuclear company or organisation. This is a crucial point for the future management of the nuclear field. Knowledge Management and Knowledge Capitalization must not be neglected, and it will be one of the major future challenge that all nuclear organisations will have to face increasingly. It will also be in line with the evolutive learning methods for future future (young) generations.

Among all the methods proposed for the KM, the MOOK tool, and related to it all the KM Processus developed and experience on the ASTRID project could be a key actor of the future KM company revolution. The major asset of this method is that it is simple, cheap and easy to apply, efficient and can be done on-line during the project evolution. Its Digital approach through Video 
rich content and PLM tool is also a significant advantage for sustainability, traceabilty while protecting Intellectual Properties, Confidential and Valuable Know-How.

After the ASTRID Project, this method is starting to be tested towards some other fields at CEA (Retired people, on-line monitoring within a research department, ...). Thus the Knowledge Management culture is progressively being implemented inside the organisation at the project team level.

\section{Author contribution statement}

G. Rodriguez: Deputy head of the ASTRID Project. Coordinator of the Knowledge Management Project. P. Amphoux: ASTRID Industrial Architect, in charge of the Computing Implementation. D. Plancq: ASTRID Industrial Architect, in charge of the Video recording management. E. Richebois: ASTRID Project Manager, in charge of the overall management of this project. F. Varaine: ASTRID Project leader, overall validation and financing of the Knowledge Management Project. P. Bigeon: Knowledge Management expert, in charge of the expertise of the Knowledge Management development.

\section{References}

1. F. Gauché, in The French Fast Reactor Program - Innovations in Support to Higher Standards, Paper No. CN-199/062, IAEACN-199, Paris, France, 4-7 March 2013, 2013

2. F. Varaine et al., Astrid project, from conceptual to basic design: progress status, in Proc. International Conference on Fast reactors and Related Fuel Cycles, FR17; Yekaterinburg, Russian Federation 26-29 June 2017 Conference ID: $50810-$ $C N-245,2017$
3. F. Varaine et al., Status of the ASTRID sodium fast reactor project at mid-term of the basic design phase, in Proc. International Congress on Advances in Nuclear Power Plants ICAPP 2018, Charlotte, USA - NC, 08-11 April 2018, 2018

4. France cancels ASTRID fast reactor project, Nuclear Engineering International, 7 October 2019, 2019

5. J.C. Astegiano, G. Rodriguez, F. Baque, Status of knowledge preservation activities on sodium cooled fast reactor in CEA, in IAEA Technical Meeting on Fast Reactor Knowledge Preservation International Project in Russia, IAEA TM-27172 and TM-26984 TWG-FR/123, Obninsk, Russian Federation, 14-18 February 2005, 2005

6. F. Baque, R\&D LMFRs knowledge preservation French project, in Proc. Technical Meeting on Operational and Decommissioning Experience with Fast Reactors, IAEA TECDOC No 1405, Cadarache, France, 11-15 March 2002, 2002, https://www-pub.iaea.org/MTCD/Publica tions/PDF/te_1405_web.pdf

7. G. Rodriguez, R\&D LMFRs knowledge preservation French project: application to sodium coolant and cover gas, in Proc. Tech. Meet. on Operational and Decommissioning Experience with Fast Reactors, IAEA TECDOC No 1405, Cadarache, France, 11-15 March 2002, 2002, https://wwwpub.iaea.org/MTCD/Publications/PDF/te_1405_web.pdf

8. F. Baque, C. Eichenbaum, French Knowledge Preservation on Sodium Fast Reactors: Feedback Experience of the MADONA Encyclopaedia project, in IAEA Technical Meeting on Fast Reactor Knowledge Preservation International Project in Russia, IAEA TM-27172 and TM26984 TWG-FR/123, Obninsk, Russian Federation, 14-18 February 2005, 2005

9. K. Schwaber, J. Sutherland, The Scrum Guide ${ }^{\text {TM }}$ : The Definitive Guide to Scrum. The Rules of the Game, November 2017. https://www.scrumguides.org/docs/scrum guide/v2017/2017-Scrum-Guide-US.pdf \#zoom=100

Cite this article as: Gilles Rodriguez, Philippe Amphoux, Daviol Plancq, Edwige Richebois, Frédéric Varaine, Phillipe Bigeon, The knowledge management on the design of a generation IV sodium fast reactor project at CEA. The case and methodology applied on the Astrid project, EPJ Nuclear Sci. Technol. 6, 53 (2020) 